Research Article

\title{
The Safety of Oral Telomerase Activator in UV-Induced Skin Cancer with A Review of Telomerase in Aging and Skin Carcinogenesis
}

\author{
Karen E. Burke ${ }^{1,{ }^{*}}$, Xueyan Zhou ${ }^{1,2}$, Yongyin Wang ${ }^{1,3}$, Huachen Wei $^{1}$
}

1. Department of Dermatology, Icahn School of Medicine, Mount Sinai Medical Center, New York, NY, 10029, USA; E-Mails: kebmdphd@gmail.com; xuzhou@wakehealth.edu; yongyin.wang@medtronic.com; huachenwei@yahoo.com

2. Department of Internal Medicine, Wake Forest School of Medicine, Winston-Salem, NC 27157, USA

3. Department of Clinical Research, Medtronic Diabetes, 18000 Devonshire St., Northridge, CA 91325, USA

* Correspondence: Karen E. Burke; E-Mail: kebmdphd@gmail.com

Academic Editor: Virginia Boccardi

Special Issue: $\underline{\text { Telomere and Telomerase }}$

OBM Geriatrics

2021, volume 5 , issue 4

doi:10.21926/obm.geriatr.2104184
Received: July 29, 2021

Accepted: November 25, 2021

Published: December 13, 2021

\begin{abstract}
The supplement telomerase activator TA-65 (purified from Astragalus membranaceus) has been shown to retard cellular senescence, boost the aging immune system, and retard agerelated symptoms. Lengthened telomeres retard aging, but because cancers often maintain longevity by lengthening telomeres, dietary telomerase activator might possibly increase tumorigenesis. This study investigated whether oral TA-65 effects the timing of onset and/or the incidence of skin cancers induced by UVB-irradiation and whether that possible effect is different if the oral supplementation is begun only after tumors are first detected clinically or if supplementation is begun before initiation of tumors as well as during and after the inciting UVB exposure. Three groups of ten Skh:1 hairless, nonpigmented mice exposed to UVB for twenty weeks were given (1) no supplementation, (2) TA-65 supplementation starting when the first UV-induced skin cancers were clinically observed, after which the UV exposure was
\end{abstract}

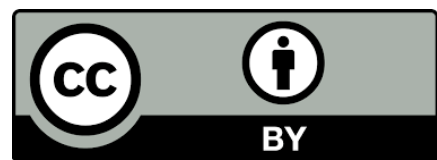

(C) 2021 by the author. This is an open access article distributed under the conditions of the Creative Commons by Attribution License, which permits unrestricted use, distribution, and reproduction in any medium or format, provided the original work is correctly cited. 
terminated, and (3) TA-65 supplementation before, during, and after UV exposure (as more tumors subsequently appeared). Except for two time points when Group 3 had borderline or statistically more tumors $\geq 2 \mathrm{~mm}$ per mouse, overall, there was no statistically significant difference in the time of onset, the incidence, or the tumor load of skin cancers with TA-65 with either timing, confirming the safety of this anti-aging supplement in this model of the most frequent human malignancy.

\section{Keywords}

Telomerase and skin cancer; telomerase and aging; telomerase activator; telomerase reverse transcriptase promoter (TERTp) mutations (TPMs) and skin cancer; UV-induced skin cancer

\section{Introduction}

Telomeres are the protective DNA protein complexes at the ends of eukaryotic chromosomes. Their function is to prevent chromosome fusion that would result in chromosomal breaks, leading to abnormal segregation of genetic information in progeny cells [1]. Telomerase is a cellular ribonucleoprotein reverse transcriptase enzyme [TERT] with a telomerase RNA template component (TERC) that adds de novo TTAGGG repeats to the G-rich 3' overhang of telomeres in late S-phase in cells proficient for the enzyme [2]. Telomere maintenance can also occur in cells without telomerase activity by alternative mechanisms [3].

Telomerase is activated during periods of dramatic cell expansion, especially during fetal development $[4,5]$. Telomerase is then repressed before birth in most tissues, although tissues requiring continual cell turnover or periods of rapid proliferation can and do up-regulate telomerase as needed $[6,7]$. Some human somatic cells are proficient in telomerase activity, such as B-cells, Tcells, and endothelial cells. Also, adult stem cells are capable of activating telomerase during tissue regeneration [7]. However, human cells lose telomeric DNA in different tissues at different rates, depending upon natural proliferation rate, age, and metabolic and oxidative stress. Postmitotic cells and tissues do not lose telomere sequences since they do not divide. Overall, the loss of telomeric DNA is relatively slow; in cross-sectional studies, humans lose telomere DNA at a rate of about 1560 base pairs per year [8]. This modest rate of base pair loss is an indication (1) that in proliferative tissues, there are only a small number of stem cells that are actually actively dividing compared to the total stem cell reserve, and (2) that other (primarily nonproliferative) tissues have mostly quiescent cells. This base pair loss reflects or possibly causes cellular aging as manifested by decreased tissue regeneration and reduced cellular function. Telomere shortening has been described as a sort of "molecular clock" that triggers cells to count their divisions so that they divide only a limited number of times in vitro, the phenomenon of all replicative senescence, characteristic of each particular cell type or strain, the so-called "Hayflick limit" [9]. However, decreased telomere length is not only an indication of natural aging $[8,10]$ but is also compounded and modified by stress [11], psychologic and metabolic [12] as well as oxidative [13]: As well as counting cell division, telomere shortening indicates the cumulative number of mutations induced by, for example, oxidative stress [13]. Von Zglinicki [13] suggests "that telomeres act as cellular sentinels for genomic damage [in order to] remove 'dangerous' cells from further proliferation." 
Infection accelerates telomere loss causing decreased efficacy of the immune system [14], especially in chronic viral infections such as cytomegalovirus (CMV) and human immunodeficiency virus (HIV). Both of these infections show symptoms of premature aging of the immune system with severe compromise to the functioning of viral cytotoxic T-cells [15-18]. Telomere shortening has been studied in vitro in human cells of genetic diseases with mutations in telomerase [19] such as idiopathic pulmonary fibrosis [20], dyskeratosis congenita [21], aplastic anemia [22, 23], and myelodysplasia [21]. All of these studies associate cellular aging and aging-related diseases with telomere shortening. Further epidemiological studies indicate that short telomeres in humans are a risk factor for common diseases such as hypertension [20], atherosclerosis [21], cardiovascular disease [21], stroke [21, 24], diabetes type 2 [24, 25], arthritis [24], osteoporosis [24], cataracts [24], cancer [21, 26], and overall mortality [27]. Razgonova et al. [28] recently reviewed the role of telomere length in the development of aging-related diseases, discussing diverse effects on mitochondrial activity, chronic stress, and circadian rhythm.

In addition to maintaining and extending telomere length, the telomerase subunit TERT has been shown to have important non-telomeric functions. As early as 1999, Elizabeth Blackburn's laboratory [29] showed that a growth crisis (failure to proliferate) in human fibroblasts (with a viral oncogene-extended lifespan in vitro) was curtailed by ectopic expression of hTERT, though the telomeres continued to shorten, demonstrating a protective function of human telomerase that allows cell proliferation without lengthening of telomeres. That ectopic expression of TERT could impart a tumorigenic phenotype to an immortal cell line without maintaining telomere length was further demonstrated by Steward, et al [30] in vitro and in vivo. Also a recent zebra fish model of dyskeratosis congenita showed that TERC acts as a transcription factor by binding to specific DNA sequences of myeloid genes to control their expression by recruiting RNA polymerase II [31]. The full spectrum of telomerase function in post-mitotic cells, in normal cells, and in tumorigenesis is currently being further investigated.

Possibly dietary supplementation with telomerase activator could be advantageous not only in retarding age-related symptoms and diseases, but also in slowing cellular senescence. A small molecule telomerase activator (TA-65) has been purified from a dried root extract of Astragalus membranaceus, a plant that has been commonly used for 2000 years in traditional Chinese medicine to protect against myocardial infarction, to boost immunity, and to retard aging. Purified from this Astragalus species, TA-65 is a single chemical entity which has been demonstrated to increase telomerase activity and lengthen telomeres in zebra finches, mice, and humans [3, 32, 33], as measured in blood monocytes and lymphocytes (particularly in the CD8+ and CD28+ populations). Safety of TA- 65 has been well documented [8, 32, 34, 35], and TA-65 has been granted "generally recognized as safe" (GRAS) status. No product-related toxicity was reported in a study of over five years (encompassing 7000 person-years) which showed that TA-65 improves markers of metabolic, cardiovascular, and bone health [8, 36]. Two later randomized placebo-controlled studies over oneyear duration showed no adverse effects $[32,34]$.

TA-65 has shown promise in delaying clinical and cellular senescence. TA-65 elongated telomers and improved the health status of older female mice without increasing the incidence of cancer [3]. In the mouse model, the slowing of senescence and the concomitant improvement of the healthspan was measured by biomarkers including improved scores in glucose tolerance test and fasting insulin levels, higher levels of red blood cells and hemoglobin count, and higher bone density as well as by clinical and histologic parameters such as enhancement of subcutaneous fat and 
epidermal thickness, increased in vitro wound healing capacity of keratinocytes, and enhanced hair regrowth in vivo after hair plucking [3]. Significantly, with these antiaging improvements in health, the mice treated with TA-65 telomerase activator did not experience any increase in cancer incidence [3].

Further research has shown a significant age-reversal of immune function with telomerase activator supplementation. In a human dietary supplement study with a total baseline population of 114 adults (average age=63yo; 72\% men), TA-65 supplementation for 6-12 months decreased the percentage of senescent cytotoxic ( $\left.C D 8^{+} / \mathrm{CD} 28^{-}\right)$T-cells and natural killer cells with a marked reduction in the percentage of short telomeres in some patients' leukocytes [8]. A greater decrease in senescent cytotoxic T-cells counts (up to a $20 \%$ reversal of senescence) was seen in cytomegalovirus (CMV) seropositive (CMV+) subjects (who initially had a higher percentage of senescent T-cells), resulting in a more "youthful" profile of circulating T-lymphocytes $\left(\mathrm{CD} 8^{+} / \mathrm{CD} 28^{+}\right)$, similar to the CMVsubjects. These results were confirmed in a recent larger placebo-controlled study of 500 individuals (average age 60yo; 54\% women) who showed a decrease of $13 \%$ in senescent cells after nine months of TA-65 supplementation, with greater decreases observed in the CMV+ patients [37]. Correspondingly, in not only aging but also in chronic HIV+ infection, dysfunctional CD $8^{+}$cytotoxic T-lymphocytes with short telomeres predominate. Incubation with the telomerase activator TA-65 (previously named TAT2 or cycloastragenol) was found to retard telomere shortening (particularly in the cytotoxic T-cells with the shortest telomeres) and to increase proliferative potential and cytokine production, thus enhancing antiviral function [16]. In in vitro CD4 and CD8 T-cells from six healthy donors, TA-65 increased the telomerase activity through regulation of MAPK-specific interactions and increased proliferative activity [38].

Telomerase activity is tightly controlled physiologically in most non-cancer cells, while most upregulation of telomerase activity in cancer cells is believed to occur via human telomerase reverse transcriptase (hTERT) promoter mutations (TPMs). Telomerase may also associate with tumor development via non-telomeric functions, as discussed above. In more than $90 \%$ of malignant tumors, telomerase activity is detected [39]. Since telomerase is so frequently up-regulated to high levels in cancer, leading to the unchecked proliferation of cancer cells [6], dietary telomerase activator could potentially be dangerous by increasing the incidence and/or growth and metastatic activity of cancer. Because many individuals take telomerase activators to retard clinical manifestations of senescence, to extend overall healthspan, and to improve immune function, this study was undertaken to determine the safety of telomerase activator TA-65 supplementation in a mouse model of skin cancer induced by UVB irradiation. This research investigated whether oral telomerase activator TA-65 has any effect on the timing of onset and/or the incidence of skin cancers induced by UVB irradiation and whether that possible effect is different if the oral supplementation is begun only after tumors are first detected clinically or if supplementation is begun before initiation of tumors as well as during UVB exposure and after UVB exposure as more tumors are subsequently detected. (Note that the former timing of supplementation corresponds to that of many individuals who begin healthy lifestyles and supplements only after they acquire a disease such as skin cancer!)

This model of UVB-induced skin cancer is of importance because the most common human malignancy is skin cancer. Indeed, the number of patients with skin cancer is equal to the number of patients with all other cancers combined. When immune suppression is given after organ transplants, many patients develop numerous skin cancers, even if they had none before. If oral 
supplementation with telomerase activator were to increase the incidence of cancer, it is likely that this adverse effect would be noted in this skin cancer model.

\section{Materials and Methods}

\subsection{Animals and Treatments}

Thirty Skh:1 hairless, nonpigmented, female mice of age 5-6 weeks were purchased from Charles River Laboratories, Wilmington, MA. The mice were pathogen-free by bacteriology and parasitology. The mice were habituated for one week before starting the supplemented diet and two weeks later UV exposure was begun, at which time they were of age 8-9 weeks and initial weight of $22.2 \pm 1.0$ $\mathrm{gm} /$ mouse. The thirty mice were randomly assigned to be housed with 5 mice/cage in the Mount Sinai Medical Center Animal Facility (New York, NY) under standard conditions of $12 \mathrm{hr}$ light/12 hr dark cycle, humidity $50 \pm 15 \%$, and temperature $22 \pm 2 \circ \mathrm{C}$. The study protocol and animal care was approved by the Animal Care Committee of Mount Sinai Medical Center in accordance with this institution's ethical guidelines.

A base diet of AIN-76A laboratory chow (supplied as pellets) was purchased from Purina Test Diet (Richmond, IN). In those mice to be given oral telomerase activator, the supplement was incorporated into the pellets to contain $60 \mathrm{mg}$ TA-65/kg chow. The TA-65 (supplied with dicalcium phosphate excipient at a 4:1 excipient/TA-65 ratio) was premixed into the pellets of chow at the beginning of the experiment to deliver an expected dose of about $7.2 \mathrm{mg} \mathrm{TA}-65 / \mathrm{kg}$ mouse weight/day. This dose is three times the dose recommended for human consumers and is comparable to the maximum amount given to human volunteers in the original health maintenance research program described by Harley et al. [8], in which the dose was started at 5 or $10 \mathrm{mg} /$ day with a few subjects given a maximal dose of up to 25 or $50 \mathrm{mg} /$ day in later months. (Only minimal increases in salutary effects were seen with the doses up to $20 \mathrm{mg} /$ day.) These doses did lengthen short telomeres and decrease the percentage of senescent cytotoxic T-cells in CMV+ patients to the levels of youthful CMV- patients, proving efficacy at these concentrations in humans. The commercially available capsules of TA-65 contain $88 \mathrm{mg} /$ capsule; the suggested personal daily dose is 1-2 capsules/day, thus delivering about $1.3-2.7 \mathrm{mg}$ TA-65/kg body weight/day. The higher doses of 10 or $25 \mathrm{mg} \mathrm{TA}-65 / \mathrm{kg}$ mouse weight/day [40] or $25 \mathrm{mg}$ TA-65/ $\mathrm{kg}$ mouse weight/day [3] have been used previously in mouse research. The unsupplemented and supplemented pellet chow was stored frozen until use. All chow for the entire experiment was from the same batch. In feeding the mice, the chow was replenished weekly and thawed weekly. The mice were exposed to UVB as described below and supplemented in three ways ( $n=10$ in each group), as shown in Figure 1: Group 1 served as a control and was given no TA-65 supplementation (base/base); group 2 was given TA-65 only after the UV exposure was terminated, which was when UV-induced skin cancers were first clinically observed (base/tel); group 3 was given TA-65 beginning two weeks before and continuing during and after UV exposure (tel/tel). 


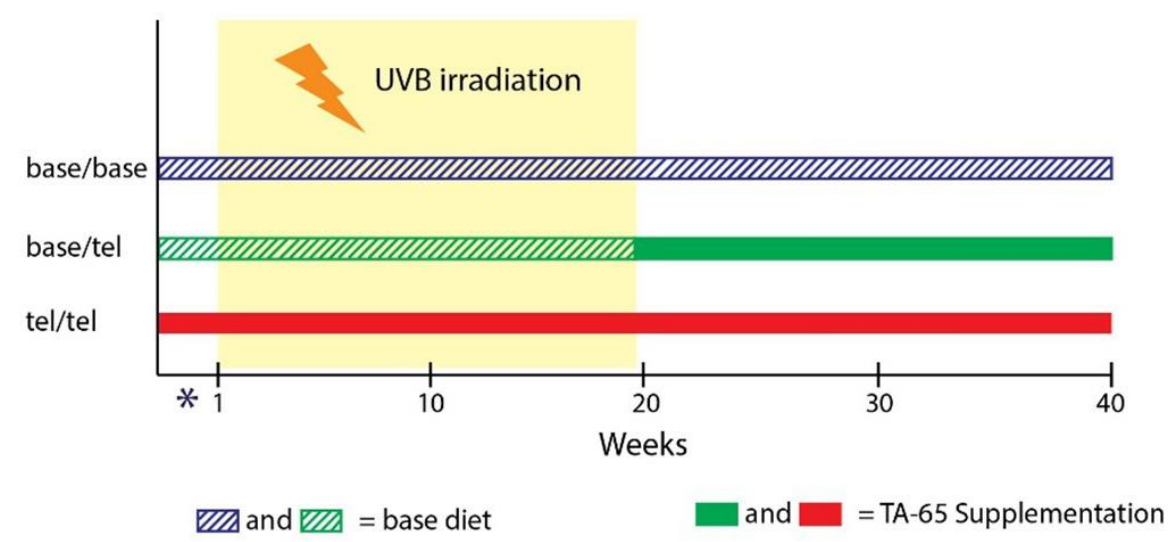

Figure 1 Timing of Oral Telomerase Activator (TA-65) Supplementation and UV Irradiation. * TA-65 supplementation was begun 2 weeks before beginning UV irradiation in the tel/tel group and at week 20 in the base/tel group. UVB irradiation was initiated starting at 15 seconds per session until mid-second week when the maintenance exposure time of 33 seconds per/session was attained. UV irradiation was terminated at week 20 when all three treatment groups had an incidence of 2 mice with at least one tumor $\geq 1 \mathrm{~mm}$.

Figure 1 shows the timing of oral telomerase activator (TA-65) supplementation and UV irradiation. After arriving at the Mount Sinai laboratory, the mice were randomly divided into 6 cages with 5 mice/cage and habituated for one week. The TA-65 supplementation was then begun two weeks before beginning UV irradiation for week 1. UV exposure was continued until the twentieth week, when all three treatment groups had an incidence of two mice with at least one tumor $\geq 1 \mathrm{~mm}$. (The very first tumor appeared in the control base diet treatment group at week 18).

With the onset of the first tumor in each initial supplementation category, each mouse was identified and distinguished with different numbers of nicks in the ear(s) for each individual mouse within each group. Within each group, the first mouse to get a tumor was mouse \#1, the second mouse, \#2, etc. Mice with no tumor at the time of tumor onset were designated numbers randomly.

Dietary consumption for each cage of five mice was measured weekly and graphed as grams food intake per gram mouse body weight per day. To monitor the general health of the mice, they were weighed weekly as a group of the mice in each cage. A graph was kept of the average weight per mouse in each of the treatment groups to monitor possible changes and differences. To check further the animals' overall health, each mouse was specifically examined weekly for general appearance (skin, muscle tone, and movement) and observed carefully for any signs of discomfort as judged by their behavior and weight.

At the termination of the experiment, the mice were euthanized with $\mathrm{CO}_{2}$ followed by cervical dislocation. The weight of each mouse was recorded; the tumors were excised and weighed. The "tumor load" ( = tumor weight $\div$ total body weight) was calculated. The final data included the one mouse in the tel/tel group that died prematurely at week 33 and the two mice in the base/tel group euthanized at week 39 for calculation of incidence and multiplicity of tumors and the two mice euthanized for calculation of tumor load. Biopsies of the skin tumors were also taken and analyzed histologically. 


\subsection{UV Irradiation}

The light source was 8 FS24T12-UVB-HO lamps (Voltaire Company, Fairfield, CT) with a predominant emitting peak at $280-320 \mathrm{~nm}$. These bulbs provide a homogenous field of irradiation. During UV irradiation, the lights were placed $40 \mathrm{~cm}$ from back of mice. The output was monitored weekly with an IL-1700 radiometer (International Light, Newburyport, MA).

For the induction of skin cancer, the irradiation was initiated at 15 seconds per session (which is equal to about $50 \%$ of the average minimal erythema dose as measured on 6 mice) and increased by 5 seconds per session until the maintenance exposure time of 33 seconds was reached within the second week, giving $0.3 \mathrm{~kJ} / \mathrm{m}^{2} /$ session. This dose is reported to be comparable to sunlight exposure for thirty minutes at noon in New York City's Central Park during the summer [41]. UVB irradiation was continued three times per week until the twentieth week, when all three treatment groups had an incidence of two mice with at least one tumor $\geq 1 \mathrm{~mm}$. This dose of UV irradiation has been shown to induce skin cancers in this breed of mouse [41].

\subsection{Evaluation of Skin Damage Induced by UV Irradiation}

During the initial exposure to UVB (until one week after the maintenance dose was attained), all animals were examined three times per week to determine the degree of short-term sun damage. Inflammation was assessed clinically by grading the degree of erythema (skin redness, the clinical manifestation of UV-induced inflammation or "sunburn"), and the number of blisters (indicative of more severe "sunburn" inflammation induced by UV exposure) on each animal was counted.

From the time that the first tumor was observed at week 18, the numbers and sizes of tumors on each animal were noted weekly. One or two raters counted the tumors (unblinded) throughout weeks 1 to 34; for weeks 35-40, two raters counted the tumors (each blinded to the individual mouse identification and its treatment group). Tumors approximately $1 \mathrm{~mm}$ in size were counted only if they were present for at least one week. Tumors $\geq 1 \mathrm{~mm}$ and $<2 \mathrm{~mm}$ and those $\geq 2 \mathrm{~mm}$ were counted separately. Tumors $\geq 2 \mathrm{~mm}$ were counted as soon as they were observed. Occasionally small tumors enlarged to co-join becoming one large tumor: In those cases, the tumor count remained two. The diagnosis of tumor was confirmed by biopsy and histological examination of clinically representative tumors from each animal. One or more tumors from each tumor-bearing mouse was biopsied for histological examination.

When mice were euthanized at the end of study after week 40 , all tumors from each mouse were excised and weighed together: The "tumor load" (= tumor weight / total body weight) was calculated. Tumor load was also measured on the two mice that were sacrificed prematurely.

\subsection{Tissue Analyses}

Biopsies of representative tumors were taken from each mouse in each treatment group to confirm the diagnoses of squamous cell carcinomas by histologic staining with hematoxylin and eosin (which stains extracellular matrix blue and cytoplasm pink). 


\subsection{Statistical Analysis}

All statistical tests were conducted with $\mathrm{SAS}^{\circledast}$ Software [42] using non-directional alternative hypotheses, which reflect the case that $a$ priori arguments could be made that TA- 65 could increase or decrease tumor growth. A p-value of 0.05 was used as the cutoff point for stating if the testing was statistically significant or not significant. P-values of 0.04 to 0.05 were interpreted as "borderline significant"; $p$-values of $>0.05$ were considered not significant.

Treatment effect on tumor incidence and tumor counts were explored using, (1) Wilcoxon rank sum tests [43], (2) Fisher's exact tests of proportion [43], (3) Kaplan-Meier time-to-event analyses [43], and (4) repeated measure ANOVA [43]. Frequency of tumor occurrence was compared using Wilcoxon rank sum tests for the base/base and base/tel groups, for the base/base and tel/tel groups, and for the base/tel and tel/tel groups. The incidence of tumors $\geq 1 \mathrm{~mm}$ and $\geq 2 \mathrm{~mm}$ was also analyzed at each week using Fisher's exact test [43]. The number of tumors $\geq 2 \mathrm{~mm}$ was analyzed by Proc GLM with pairwise contrast estimates among groups [43].

Time to observation of the first tumor $\geq 1 \mathrm{~mm}$ and $\geq 2 \mathrm{~mm}$ was compared across the three treatment groups (base/base, base/tel, and tel/tel) by two separate Kaplan-Meier survival analyses [43]. In each analysis, the log rank statistic was used to evaluate the omnibus hypothesis of equality in survival function among all three groups, with follow-up pairwise comparisons in the presence of a significant omnibus effect.

Another separate statistical analysis was done to compare results of the tumor counts by two different raters, each blinded with respect to mouse identification in its treatment group. Exploratory analysis on treatment effects for four variables ((i) total tumors for Rater 1, (ii) total tumors for Rater 2, (iii) tumors $\geq 2 \mathrm{~mm}$ for Rater 1 and (iv) tumors $\geq 2 \mathrm{~mm}$ for Rater 2) were performed using (1) repeated measures of "analyses of variance" (ANOVA) and (2) Wilcoxon rank sum tests [43]. In the repeated measures of ANOVAs, time served as the within-subject (or repeated) factor; group (base/base, base/tel, and tel/tel) served as the between-subject factor. Three effects were analyzed: (a) time, (b) group, and (c) the time $x$ group interaction. In addition, a contrast was performed between the combined base/tel and tel/tel groups and the base/base group.

\section{Results}

\subsection{Mouse Growth Rate and Food Intake}

As seen in Figure 2a, the average dietary intake was the same in all three treatment groups $(0.119$ $\mathrm{gm} / \mathrm{gm}$ body wt/day). Note that food intake could only be measured per cage; the food intake of each individual mouse could not be determined. Throughout the experiment, the five mice in each cage were weighed together. Only at week 40 were they weighed individually. At week 30 (when the mice were fully mature and not yet possibly debilitated by their skin cancers) the average body weight was $30.5 \pm 1.8 \mathrm{gm} /$ mouse. As can be seen by the graph in Figures $2 \mathrm{a}$ and, $2 \mathrm{~b}$, the dietary consumption and the body weight of the mice was essentially the same in all three treatment groups. Thus, dietary telomerase activator TA-65 did not significantly affect food intake and consequent body weight. There were no symptoms of failure to thrive in any mice in any group: All animals had normal skin in non-UV-exposed areas, normal muscle tone, and normal movement and activity throughout the 40-week experiment. With the exception of only two mice (see below), both 
supplemented and non-supplemented mice thrived and did not become debilitated by their tumor load.
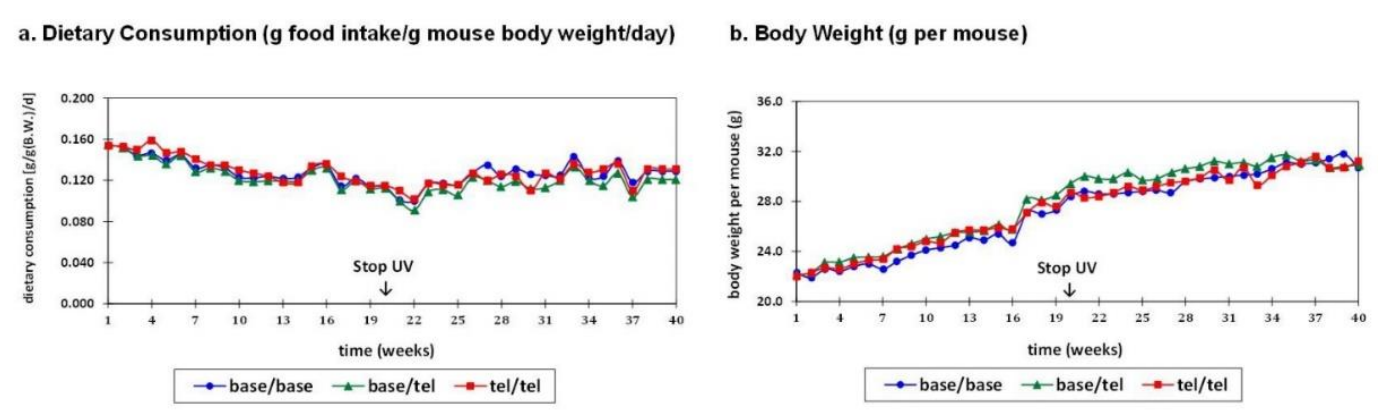

Figure 2 The weekly dietary consumption and body weight and food intake of Skh:1 mice without and with TA-65 supplementation. (a) The food intake was measured per cage; the food intake of each individual mouse could not be determined. (b) Throughout the experiment, the five mice in each cage were weighed together. Only at week 40 were they weighed individually.

\subsection{UVB-Induced Carcinogenesis}

Although the mice showed very minimal erythema after the second exposure to UVB, there was no difference in degree of erythema in any of the treatment groups, and no mouse had any blistering from the initial or subsequent UV exposure.

During the course of the 40-week experiment, only one mouse died prematurely (tel/tel group, 33 rd week). Because the body was destroyed, no data to calculate tumor load on that one mouse was available. Two mice (both from base/tel group) were euthanized at week 39 because of severe body weight loss: The tumor load of one of these mice was quite high (8.7\%); the second had a tumor load equal to $2.0 \%$ (the average tumor load seen in this study). Because the experiment was planned to be terminated only days later, euthanizing early was not expected to change tumor count or tumor load significantly. All other mice showed no signs of discomfort or change in muscle tone, movement, or activity.

Skin tumors were induced in all animals exposed to UVB irradiation. The Skh:1 mice characteristically developed multiple tumors. Some animals were riddled with tumors (up to 25-30 small tumors $\geq 1 \mathrm{~mm} /$ mouse and 7-9 larger tumors $\geq 2 \mathrm{~mm} / \mathrm{mouse}$ ) and others had fewer large tumors. Clinically and histologically these tumors were fibrosarcomas (spindled-cell squamous cell carcinomas with marked invasion of the dermis and many multinucleated anaplastic spindle-shaped cells), or they were keratoacanthoma-like (with ulceration and marked hyperkeratosis and acanthosis of the epithelium and with invasive endophytic papillary projections). Whorls of cornfield cells and atypical keratinocytes were noted with dense dermal inflammatory infiltrates. All tumors biopsied were squamous cell carcinomas varying from well differentiated to poorly differentiated. No benign papillomas persisted for more than one week.

Figure $3 a$ illustrates the tumor incidence, the number of mice with tumor(s) $\geq 1 \mathrm{~mm}$ detected in each of the three irradiated groups of mice. Clearly the time of onset of tumors was similar in all three groups as confirmed by Kaplan-Meier analysis (see Section 3.3). The first tumor appeared in the base diet treatment group at week 18. UV exposure was discontinued after week 20 - after at 
least two mice in each group had at least one tumor $>1 \mathrm{~mm}$. It is evident that even after UVB radiation was terminated, the mice continued to develop tumors. By week 28 , every mouse in the base/tel and in the tel/tel groups had at least one tumor $\geq 1 \mathrm{~mm}$. One mouse in the base/base group had no tumor $\geq 1 \mathrm{~mm}$ until week 33 . These differences were not statistically significant, as discussed below in Section 3.3. Kaplan-Meier analysis showed no statistically significant difference among the three treatment groups in the time of onset of skin tumors $\geq 1 \mathrm{~mm}$ or in incidence of tumors $\geq 1 \mathrm{~mm}$ (as discussed below). Although in Figure $3 \mathrm{~b}$ the time of onset of tumors $\geq 2 \mathrm{~mm}$ appears earlier in the tel/tel group than in the two other treatment groups, Kaplan-Meier analysis demonstrated that this apparent difference was not statistically significant. As seen in Figure 3b, by week 27 all groups had at least two mice with a tumor $\geq 2 \mathrm{~mm}$. At weeks 24 to 27 and weeks 32 to 36 , there appears to be a higher incidence of tumors $\geq 2 \mathrm{~mm}$ in the tel/tel treatment group, but repeated measure ANOVA analysis showed that these differences were not statistically significant because the appearance in the graph reflects only a difference of one or two mice. That these differences were not significant was confirmed by Fischer's Exact test except for only the comparison of base/base vs. tel/tel at week 26 which was borderline significant ( $p=0.0433$ ) (as shown below in Table 1 and Table 2 and Section 3.3 of statistical analysis results).

a. The percentage of mice in each ten-mice treatment group with a tumor $\geq 1 \mathrm{~mm}$

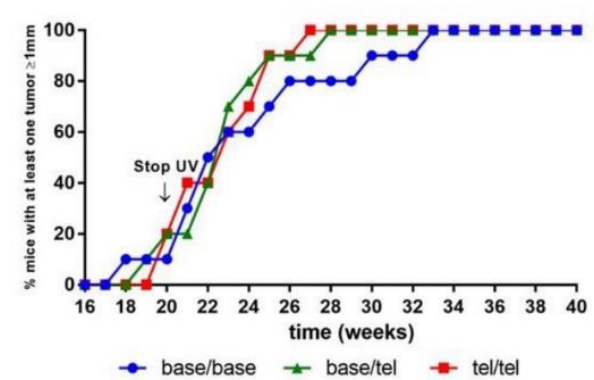

b. The percentage of mice in each ten-mice treatment group with a tumor $\geq 2 \mathrm{~mm}$

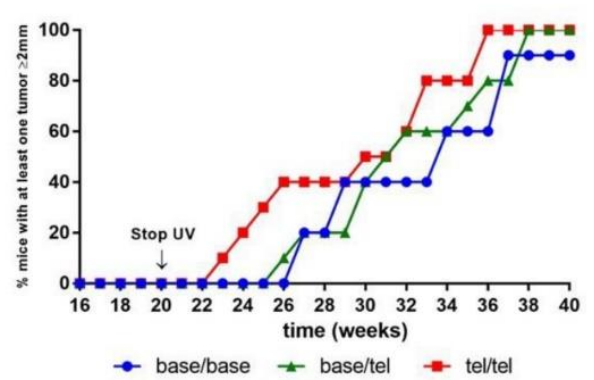

Figure 3 The weekly incidence of UVB-induced skin tumors. UVB irradiation was discontinued after week 20. The number of mice with at least one tumor were noted weekly, and the number of tumors on each mouse was counted. Tumors $\geq 1 \mathrm{~mm}$ in size were counted only if they were present for at least one week.

Table 1 Analysis by Fisher's Exact Test [43] in incidence of tumors $\geq 2 \mathrm{~mm}$.

\begin{tabular}{lll}
\hline & $p$-value* \\
\hline Week & base/base vs. base/tel $^{*}$ base/base vs. tel/tel \\
26 & Not significant & \\
33 & Not significant & $0.0433^{\mathrm{b}}$ \\
36 & $0.0867^{\mathrm{c}}$ & $0.0750^{\mathrm{c}}$ \\
\hline
\end{tabular}

${ }^{*}$ This table lists only weeks with $p$-values $<0.1$.

a All $p>0.1053$ for all other comparisons

at all other weeks of trial

with no specific $p$-value listed here

${ }^{\mathrm{b}}$ Borderline significant difference

${ }^{\mathrm{C}}$ Not significant difference 
Table 2 Contrast estimate results [43] for tumor incidence ( $\geq 2 \mathrm{~mm})$ among pairwise groups.

\begin{tabular}{ll}
\hline contrast groups & $p$-values \\
\hline base/tel vs. base/base & 0.6056 \\
tel/tel vs. base/base & 0.1903 \\
tel/tel vs. base/tel & 0.2305 \\
\hline
\end{tabular}

Figure 4 shows the tumor multiplicity: Figure 4 a illustrates the number of tumors $\geq 1 \mathrm{~mm}$ per mouse observed in each of the three treatment groups of irradiated mice, and Figure $4 \mathrm{~b}$ shows the multiplicity of larger tumors (the number of tumors $\geq 2 \mathrm{~mm}$ per mouse) detected in each of the three groups of irradiated mice. From these graphs it can be seen that even after UVB radiation was terminated, the mice continued to develop more tumors. Although in Figures $4 a$ and $4 b$, there seem to be some differences among the three treatment groups in multiplicity (i.e., number of tumors per mouse) when counting all tumors $\geq 1 \mathrm{~mm}$ (Figure $4 \mathrm{a}$ ) or when counting only larger tumors $\geq$ $2 \mathrm{~mm}$ (Figure $4 \mathrm{~b}$ ), the only statistically significant differences were at weeks 25 and 26 with more tumors $\geq 2 \mathrm{~mm}$ in the tel/tel group compared with the base/base group. A discussion of this statistical analysis follows in Section 3.3.

a. The mean number of tumors $\geq 1 \mathrm{~mm}$ per mouse in each ten-mouse treatment group

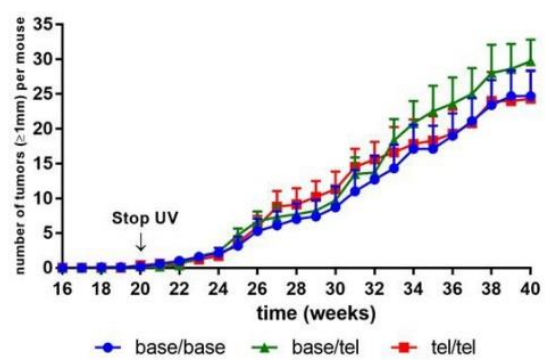

b. The mean number of tumors $\geq 2 \mathrm{~mm}$ per mouse in each ten-mouse treatment group

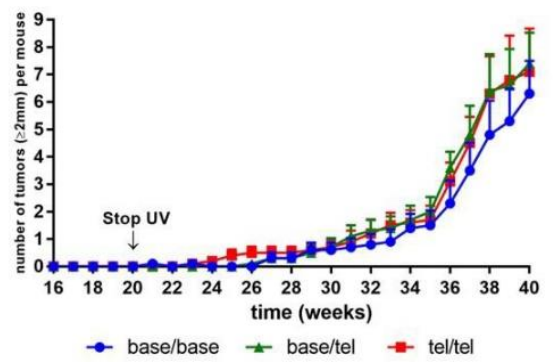

Figure 4 The weekly multiplicity of skin tumors. UVB irradiation was discontinued after week 20. Each week tumors $\geq 1 \mathrm{~mm}$ and $<2 \mathrm{~mm}$ and those $\geq 2 \mathrm{~mm}$ were counted separately. Tumors $\geq 2 \mathrm{~mm}$ were counted as soon as they were observed. Occasionally small tumors enlarged to co-join, becoming one large tumor: In those cases, the tumor count remained two. The diagnosis of tumor was confirmed by biopsy and histological examination of clinically representative tumors from each animal.

The average tumor load per mouse for each treatment group at the end of study is shown in Figure 5. Although the tumor load of the base/tel group (equal to 1.7\%) is slightly less than that of the base/base group (equal to 1.9\%) and that of the tel/tel group (2.2\%) is slightly higher, these minimal differences are not statistically significant by ANOVA tests $(F=0.24, p=0.7864)$. The standard errors were rather high since each treatment had one (base/tel) or two (base/base and tel/tel) mice with an exceptionally high tumor load. 


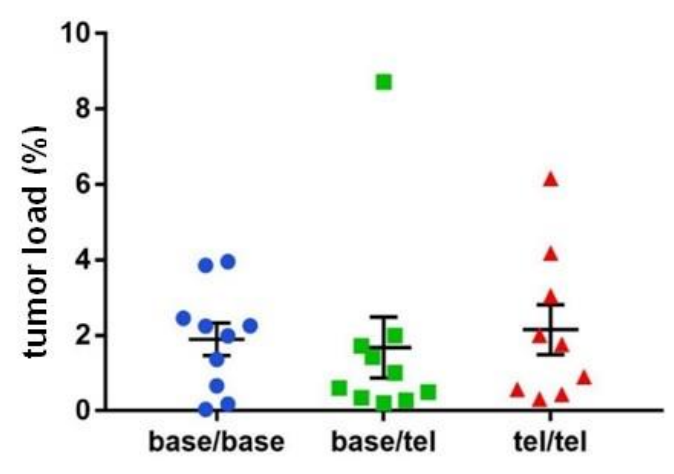

Figure 5 The effect of oral TA-65 on UVB-induced skin tumor load in each 10-mouse treatment group at week 40 . The bar represents mean \pm SEM (standard error of mean) along with the individual value plotted. Tumor load (\%) was calculated using the formula: tumor load $(\%)=$ tumor weight (gram) $\div$ total body weight (gram) $\times 100$. Note that one mouse from the tel/tel group died prematurely at week 33 , so the tumor load for that one mouse could not be determined.

\subsection{Statistical Analysis Results}

The Kaplan-Meier analysis showed no significant differences among the treatment groups in the time of clinical observation of the first tumors $\geq 1 \mathrm{~mm}(p=0.3575)$ or $\geq 2 \mathrm{~mm}(p=0.1222)$. Therefore there was no significant difference in the time of onset of the first tumors $\geq 1 \mathrm{~mm}$ or $\geq 2 \mathrm{~mm}$ among the treatment groups.

As enumerated in Table 1, the Fisher's exact test results indicated only one borderline significant difference in the incidence of tumors $\geq 2 \mathrm{~mm}$ at week 26 (base/base vs. tel/tel, $p=0.0433$ ). Differences at week 33 (base/base vs. tel/tel, $p=0.0750$ ) and at week 36 (base/base vs. tel/tel, $p=$ 0.0867 ) were not significant. No other significant differences were observed (all $p>0.1053$ ). There were no significant differences among the groups in incidence of tumors $\geq 1 \mathrm{~mm}$. The repeated measure ANOVA analysis performed for tumors $\geq 2 \mathrm{~mm}$ showed no treatment effect overall among the three treatment groups in tumor incidence by Proc Genmod (Chisq=1.97, $p=0.3730$ ) and the $p$ values for contrast estimate results among groups listed in Table 2 were all $>0.05$. (Note that all calculated $p$-values were $>0.19$.) Therefore TA-65 treatment has no statistically significant effect on tumor incidence.

As shown in Table 3, the Wilcoxon results indicated only one borderline and one significant difference in mean number of tumors $\geq 2 \mathrm{~mm}$ between the base/base and tel/tel groups at week 25 $(p=0.0468)$ and week $26(p=0.0239)$, respectively. No significant differences were observed in the mean number of tumors $\geq 2 \mathrm{~mm}$ at week 24 (base/base vs. tel/tel, $p=0.0918$ ), week 33 (base/base vs. tel/tel, $p=0.0887$ ), and week 36 (base/base vs. base/tel, $p=0.0717$ ) as well as other weeks of trial. No significant differences were observed among the groups in number of tumors $\geqq 1 \mathrm{~mm}$ (all p > 0.1291 except at week 25 (base/base vs. base/tel, $p=0.0993$ ). 
Table 3 Analysis by Wilcoxon Test [43] in mean number of tumors $\geqslant 2 \mathrm{~mm}^{\mathrm{a}}$.

\begin{tabular}{lll}
\hline & $p$-value* & \\
\hline Week & base/base vs. base/tel $^{*}$ base/base vs. tel/tel & $0.0918^{\mathrm{b}}$ \\
24 & Not significant $^{\mathrm{a}}$ & $0.0468^{\mathrm{d}}$ \\
25 & $0.0993^{\mathrm{b}, \mathrm{c}}$ & $0.0239^{\mathrm{e}}$ \\
33 & Not significant $^{\mathrm{a}}$ & $0.0887^{\mathrm{b}}$ \\
36 & Not significant $^{\mathrm{a}}$ & Not significant $^{\mathrm{a}}$ \\
\hline
\end{tabular}

*This table lists only weeks with $p$-values $<0.1$.

${ }^{a}$ All $p>0.129$ for all other comparisons

at other weeks of trial

with no specific $p$-value listed here

${ }^{\mathrm{b}}$ Not significant difference

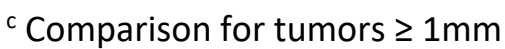

d Borderline significant difference

e Significant difference

The tumor $\left(\geq 2 \mathrm{~mm}\right.$ ) multiplicity by repeated measure ANOVA was performed with SAS ${ }^{\oplus}$ Procedure GLM with week as repeated measurement within subjects. The least square means method was used for pairwise comparison at each week to determine whether treatment effect was significant. An almost borderline significant model effect at week $25(F=3.27, p=0.0534)$ and a borderline model effect at week 26 ( $F=3.50, p=0.0445)$ were detected, and the pairwise comparison results are shown in Table 4. For example, significant differences were observed at week 25 $(p=0.0353)$ and at week $26(p=0.0188)$ between base/base vs tel/tel (Table 4$)$ which are similar to Wilcoxon p-value 0.0468 at week 25 and 0.0239 at week 26 (Table 3). No statistically significant differences were observed in any other weeks. No treatment effect was observed among the three treatment groups in tumor multiplicity in tumors $\geq 1 \mathrm{~mm}$.

Table 4 Analysis by reported measure ANOVA [43] in mean number (tumors/mouse) $\geq$ $2 m m^{\mathrm{a}}$.

\begin{tabular}{lll}
\hline & p-value & \\
\hline Week & base/base vs. base/tel $^{*}$ & base/base vs. tel/tel \\
24 & Not significant $^{\mathrm{a}}$ & Not significant $^{\mathrm{a}}$ \\
25 & Not significant $^{\mathrm{a}}$ & $0.0353^{\mathrm{b}}$ \\
26 & Not significant $^{\mathrm{a}}$ & $0.0188^{\mathrm{b}}$ \\
\hline
\end{tabular}

*This table lists only weeks with $p$-values $<0.1$.

a $p>0.3$ for all other comparisons

at all other weeks of trial

${ }^{\mathrm{b}}$ Significant difference

Thus overall, the analyses did not demonstrate compelling statistical evidence to support either a significant decrease or increase in tumor incidence or tumor number by oral supplementation with 
TA-65 either when given only after tumors were clinically noted or when given before, during, and after the UVB irradiation which induced these skin tumors.

Analysis of tumor multiplicity for both all tumors $\geq 1 \mathrm{~mm}$ and only larger tumors $\geq 2 \mathrm{~mm}$ by two raters (each blinded) showed no significant differences between treatment groups (base/base vs. tel/tel or base/tel vs. tel/tel) based on the t-test results (all $p>0.18$ ). Only one comparison of data from Rater 2 was significantly different based on the Wilcoxon non-parametric test for base/base vs. base/tel at week 36 for tumors $\geq 2 \mathrm{~mm}$ : one-sided exact $p=0.0495$. All other comparisons showed no significant difference among treatment groups (all $p>0.14$ ).

In analyzing tumor load at the end of the study (at week 40), there was no significant difference in tumor load between treatment groups and the control group at the end of the study $(F=0.24$; $p=0.7864)$. Because one mouse in the base/tel group had an exceptionally large tumor load and two mice in both the base/base and the tel/tel groups similarly had particularly large tumor loads, the standard errors were high.

\section{Discussion}

Skin cancer is by far the most frequent human malignancy: One in five Americans will develop skin cancer by the age of 70 [44]. About $90 \%$ of nonmelanoma skin cancers [45] and about $86 \%$ of melanomas [46] are associated with exposure to solar UV. Basal cell carcinoma is the most common and squamous cell carcinoma, the second most common nonmelanoma skin cancer $(80 \%$ and $20 \%$, respectively) with 4.3 million and $>1.0$ million cases per year [47], resulting in 3000 [48] and 15,000 deaths [49] per year, respectively, in the USA. Although telomerase activity is usually suppressed in adult somatic cells, cancer cells often show reactivation of telomerase which is thought to be responsible for their rapid proliferation. Recent studies indicate that indeed telomerase activation plays a role in the onset and progression of basal and squamous cell carcinomas as well as of melanomas [50].

Mice are frequently used in studies of photocarcinogenesis of the skin because squamous cell carcinomas are reproducibly induced [41,51-54]. Obviously, hairless mouse breeds are preferred to eliminate the necessity to shave. With their thin stratum corneum [55] and limited capacity to repair UV-induced pyrimidine dimers [56, 57], Skh:1 hairless mice are particularly vulnerable to skin cancer. Furthermore, these mice are not immunologically compromised and can tolerate large tumor loads without failure to thrive $[41,51,54]$. Since skin cancer is by far the most common human malignancy, this mouse model can be used to check the safety of telomerase activator by determining whether UVB-induced skin cancer incidence and growth is increased by telomerase activator supplementation.

Although the concentrations of TA-65 in the skin were not directly measured in this study, prior research has shown that oral supplementation does effectively deliver TA-65 to the skin with evidence of telomerase activation. Preclinical testing of oral TA-65 fed to pigs indicated the presence of TA-65 in the skin by both biopsy and by analysis of the skin collected after sacrifice (Personal Communication, 2020 [58]), demonstrating that oral TA-65 does result in effective concentrations in skin cells. Two independent studies show that TA-65 does activate telomerase in keratinocytes in vivo $[3,8]$. Mice fed TA-65 - and not the control - exhibited significant alterations in the subcutaneous fat layer and more proliferation of epidermis [3]. Also, female Sprague-Dawley rats increased mRNA levels of TERT and telomerase associated protein (Tep1) in the cerebral prefrontal 
cortex and hippocampus after oral supplementation with TA-65 following repetitive traumatic brain injury; unsupplemented controls showed no increase [59]. Another demonstration of tissue distribution of TA-65 after oral supplementation was shown in a transgenic mouse model of Parkinson's disease [40]: Oral TA-65 increased TERT protein in the brain neocortex and hippocampus, resulting in decreased $\alpha$-synuclein protein levels and improvement of motor functions. Such effects in these four studies would not have been possible without the circulatory distribution of TA-65.

In our study the seeming differences observed in Figure $3 \mathrm{~b}$ showing tumor incidence at weeks 25 and 26 may imply that TA-65 might have some influence on tumor initiation and progression, statistical analysis comparing base/base vs. tel/tel by Fisher's Exact Test showed only one statistically significant increase in incidence of tumors $\geq 2 \mathrm{~mm}$ in the tel/tel group. This comparison by Wilcoxon Test for mean number of tumors $\geq 2 \mathrm{~mm}$ similarly showed only one statistically significant increase at week 26 and a borderline statistically significant increase at week 25 . Reported measure ANOVA indicated statistically significant increases in mean number of tumors $\geq$ $2 \mathrm{~mm}$ only at weeks 25 and 26 . Except for these two times, overall statistical analysis showed that TA-65 has no treatment effect on tumor multiplicity considering sample size is small and there is no remarkable difference at other times in the 40-week study (Tables 3 and 4).

The TA-65 supplementation did not cause any noticeable adverse symptoms in the mice. The non-supplemented and supplemented mice appeared of normal weight and showed normal movement and activity with no sluggishness throughout the 40-week experiment. Both unsupplemented and supplemented mice thrived. All had normal, healthy skin on non-UV-exposed sites, as well as normal muscle tone.

No mouse in any treatment group showed symptoms of sunburn with significant erythema or blistering during the initial or subsequent UV irradiation. This demonstrates that oral TA-65 is not sun-sensitizing (as are many oral medications) - further testimony confirming the safety of TA-65.

These experiments demonstrate that TA-65 supplementation did not affect the incidence or multiplicity of tumors induced by UVB-exposure in this mouse model, whether given only after tumors are first detected clinically or if supplementation is begun before initiation of tumors as well as during and after the inciting UVB exposure. Overall there was not a statistically significant difference among the treatment groups in time of onset of skin tumors, incidence of tumors (number of mice with at least one tumor), multiplicity of tumors (number of tumors/mouse), or tumor load. Although Figure $3 \mathrm{~b}$ seems to show that there is a higher incidence of tumors $\geq 2 \mathrm{~mm}$ for the tel/tel treatment group for the few weeks 22 to 29 and 32 to 34, this difference was not statistically significant except at week 26 when there was a borderline statistically significant increase in tumor incidence. In tumor multiplicity, only at weeks 25 and 26 were there borderline or statistically significantly more tumors $\geq 2 \mathrm{~mm}$ in the tel/tel group compared with the base/base group. Also, one mouse in the tel/tel group died in week 33, so for that one mouse, tumor number could not further increase and tumor load could not be determined. This is a limitation that may mean that there may have been more tumors in the tel/tel group. However, overall apparent differences in tumor load were not statistically significant.

These results are very reassuring, since oral supplementation with telomerase activator might have greatly increased the incidence of UV-induced skin cancer. Cancer cells proliferate rapidly and typically have a high level of telomerase which might override natural protective anti-proliferative or apoptosis signals to enable and/or enhance cancer growth. Thus cancer cells might have a significant growth advantage in the presence of supplemental telomerase activator. 
Possible evidence of this growth advantage was observed by Stampfer et al. [60]: Growthinhibiting, anti-proliferative actions of tumor growth factor- $\beta$ (TGF- $\beta$ ) were not effective in cultured, telomerase-positive human breast epithelial cells, whereas the control, telomerase-negative breast epithelial cells were sensitive to TGF- $\beta$. Ectopic expression of hTERT in the telomerase-negative cells was sufficient to convert these TGF- $\beta$ responsive cells to a TGF- $\beta$-resistant state.

Telomerase reverse transcriptase (TERT), the ribonucleoprotein enzyme that synthesizes telomerase DNA (TTAGGG hexamers), is responsible for maintaining telomere length [61]. TERT promoter (TERTp) mutations (TPMs) create binding sites for transcription factors that result in telomerase expression and increased telomere length and stability, preventing senescence and apoptosis of cancer cells, thereby allowing cancer cells to divide. Recurrent somatic TPMs have been found to be high in many human cancers [62], particularly those of the central nervous system [63, 64], bladder cancers [65], and follicular cell-derived thyroid cancers [66], as well as in cutaneous melanomas $[67,68]$. The signature UV- radiation-induced mutations (cytidine-to-thymidine (C $\rightarrow T$, $\mathrm{CC} \rightarrow \mathrm{TT}$ )) do generate TPMs that are seen in melanomas [69], cutaneous squamous cell and basal cell carcinomas [70-72], periocular basal and squamous cell carcinomas [73], and conjunctival intraepithelial neoplasia [73]. In fact, in analyzing melanomas with contiguous benign nevus precursors, TPMs were identified in areas of the tumor thought to be intermediate between nevus and melanoma [74].

Recently published research has demonstrated that indeed TPMs are significantly more common in both primary and recurrent melanomas compared with recurrent nevi and that the relative number of TPMs can help distinguish recurrent nevi from recurrent melanomas [75]. Also distinguishing between Spitz nevi, atypical Spitz tumors, and Spitzoid melanomas can be histopathologically challenging. Recent analysis indicates that Spitzoid lesions with TPMs exhibit a more clinically aggressive course, so TPMs can serve as an additional predictive marker [76].

Further experiments by De Unamuno et al. [77] analyzed not only TPMs, but also telomerase expression at the protein level. Telomerase protein was found in all melanocytic lesions, but is higher in melanomas than in nevi. A heterogeneous pattern of expression is linked to a more aggressive tumor. Curiously, the mutational state of the TERT gene did not correlate with differences in telomerase expression. Nevertheless, TERTp mutation status may serve as an independent prognostic factor in cutaneous melanoma [78]. A new in situ hybridization technique, RNAscope, can detect hTERT mRNA in formalin-fixed paraffin-embedded tissue [79]. In comparing 17 melanomas and 13 benign nevi, hTERT mRNA was indeed expressed more abundantly in melanomas compared to benign nevi with correlation to Breslow thickness and Ki67 proliferation index [79], suggesting prognostic potential. After analysis of 86 primary melanomas, 72 melanocytic nevi, and 40 diagnostically difficult melanocytic lesions, Thomas et al. [39] conclude that TERT positivity as a test for melanoma versus nevis has an accuracy of $87 \%$, a sensitivity of $78 \%$, a specificity of $99 \%$, a positive predictive value of $99 \%$, and a negative predictive value of $79 \%$.

Although there is often a familial association in the tendency to acquire an environmentallyinduced melanoma, TPMs were not identified in a study of 228 hereditary cutaneous melanoma families, though $2 \%$ of individuals from these families had mutations in POT1, a part of the shelterin complex that binds to telomerase to protect these chromosomal ends [80]. Other studies confirmed that TPMs are rare in familial melanoma $[69,81]$.

Interestingly in analyzing TERTp mutations in primary and secondary melanomas, the mutation status was discordant between the primary tumor and metastasis [82]. TERTp mutated melanomas 
tended to be thicker, have a higher mitotic count, and higher patient age than TERTp wild-type tumors, but there was no significant association with reduced survival. As in the De Unamuno et al. [77] study cited above, TERT protein level did not correlate with mutational status. The telomerase protein level showed discordance between primary and first mutational lesions and was significantly associated with reduced patient survival [82]. Furthermore, TERT mutations vary in gene expression and impact on absolute telomere length: For example, in evaluating 60 melanoma cell lines, mutations at positions $-124 / 125$ and -146 were found to be associated with the highest levels of TERT gene expression but had no impact on telomere length while the common mutation at position -245 resulted in long telomere length [83]. As Shaughnessy et al. [83] conclude, TPMs comprise a "complex mutational landscape." The failure of TERT promoter to correlate consistently with TERT expression and telomere length suggests an alternative method whereby tumor cells escape the critical shortening of telomeres [83].

The discrepancy may be because senescence-mediated aging is clearly distinct from epigenetic aging [84]. By stimulation of telomerase to lengthen telomeres, cells bypass replicative senescence and fortunately rejuvenate. This longer lifespan ironically allows more time for the inherent processes of epigenetic aging to occur [84]. For example, epigenetic aging induced by histone methylation (or acetylation or phosphorylation) alters chromatin accessibility - not only to the expression of TERT, but also to the expression of other transcription factors [84, 85]. Certainly, exposure to environmental pollutants and infectious agents affects the endogenous cascades that cause epigenetic aging.

Nonmelanoma skin cancer (NMSC) is the most common of all cancers, with distinct subtypes basal cell carcinoma (BCC), cutaneous squamous cell carcinoma ( $\mathrm{CSCC}$ ), and Merkel cell carcinoma (MCC) - all of which invade locally into deeper layers of the skin and can metastasize. Actinic keratoses (AK) are precancers (precursors to cSCCS), and Bowen's Disease (BD) is CSCC in situ. Each type has distinct causes (exposure to ultraviolet (UV) light and pollution, genetic heritage, infectious agents) and distinct clinical and histopathological presentations and progression. Telomere length varies within each type of NMSC, and even between original tumors and metastases [86].

Interestingly, a recent study of 53 biopsied AK's in 29 patients, TERTp mutations were detected in $21 \%$ of the AK's; $83 \%$ of these TPM+ AK's also had increased p53 expression [87]. Treatment with daylight-mediated photodynamic therapy decreased the histologic grading of dysplasia as well as the frequency of TPM mutations and p53 expression. This study included 20 tumors, of which $30 \%$ showed TPMs and 11 SCCs, of which 45\% carried TPMs.

Both long and short telomeres have been noted in cutaneous squamous cell carcinoma. TPMs have been identified in $32-70 \%$ of squamous cell carcinomas [88]. (These mutations are most frequently UV-signature mutations, thus confirming the role of UV exposure.) No significant correlation was found between the TPMs and clinical or pathologic characteristics, though these mutations did predict recurrences and metastases [88]. Other recent studies have also demonstrated that TPM+ squamous cell carcinomas have higher risks for local recurrence and lymph node metastasis [89]. TPMs may in the future be included in the prognostic assessment of patients with cutaneous squamous cell carcinomas.

In the study presented here, fortunately oral telomerase TA-65 was not photosensitizing and did not increase UVB-induced skin cancer, thus confirming the safety of TA-65 supplementation. This study is limited because telomere length and the precise proliferation of cancer cells using PCNA or Ki67 were not analyzed. However, the fact that oral telomerase activator TA-65 did not increase the 
incidence of UVB-induced skin cancer is of particular significance because of the high prevalence of skin cancer. Skin cancer is by far the most common type of cancer, and its incidence is rising [90-94]. Indeed, each year there are more new cases of skin cancer than the combined incidence of breast, prostate, lung, and colon cancer [90]. Also, the fact that Gonzalez-Suarez and colleagues [95] have shown that in vivo overexpression of the mouse telomerase reverse transcriptase MTERT in basal keratinocytes promoted proliferation of these cells (despite the observation that the keratinocyte telomeres, already very long, were not appreciably changed in length upon expression of mTERT) suggests that basal cell and squamous cell skin cancers could be particularly susceptible to adverse effects from telomerase activation. Fortunately, this proliferation of basal cells and keratinocytes known to be induced by UVB-exposure of human skin was not observed in the mouse model studied here.

Oral telomerase activator supplement TA-65 may prove to be very beneficial by reducing the load of very short telomeres, thereby counteracting the telomere shortening, which occurs with natural aging and physiologic stress. Human subjects taking TA-65 for one year attained a net increase of telomere length of $530 \pm 180$ base pairs per year, rather than an annual loss of about 60 base pairs [32]. Maintenance of telomeres possibly has been proven to slow many of the manifestations of aging, which lead to declining health and an increased risk of disease - particularly in enhancing immune function with aging and with viral infection [8, 17, 36, 37]. In fact, "highperforming" centenarians (>100 years old) were found to have (i) longer telomeres, (ii) greater proliferation of their T-cells with in vitro stimulation (markedly better not only when compared to "low-performing" centenarians, but also when compared to 67-83 year-old controls), and (iii) enhancement of telomerase following stimulation with expression of many genes related to telomere length [96].

Thus, the possible advantages of telomerase activator to overall health are potentially extraordinary, but safety must be tested. The observation that oral telomerase activator does not increase the incidence or proliferation of the most prevalent human cancer - UVB-induced skin cancer - certainly further supports the safety of TA-65. The fact that oral telomerase activator TA65 was found to be safe in this one model (used frequently in cancer investigation) gives evidence for the safety of this supplement.

Further studies are currently underway in human volunteers to measure other parameters of aging that may be slowed by oral TA-65. Indeed, even very low (nanomolar) levels of TA-65 have been shown to be effective in maintaining telomere length $[8,36,37]$. Other new telomerase activators are currently being investigated for therapeutic and antiaging efficacy with monitoring for safety, including a Centella asiatica extract formulation, oleanotic acid, mastinic acid, and other proprietary nutrients [97]. More than 200 compounds have been isolated from Astragulus membranaceus including 14 polysaccharides, 161 saponins, many flavonoids, as well as other compounds (such as astragalactosides) - many of which have been proven to have not only antiaging but also even anti-carcinogenic efficacy in animal and in vitro human cell studies [98]. Antineurodegenerative, anti-vascular disease, immunomodulatory, and anti-oxidative effects have been demonstrated for many of these specific compounds, as excellently reviewed by Liu et al. [98]. With the further evidence of safety demonstrated by this research, the ultimate hope is that taking a telomerase activator supplement will lead to the prevention or inhibition of the degenerative diseases of aging so that we can indeed "add years to our life and life to our years." 


\section{Conclusion}

The rates of tumor formation, the incidence and multiplicity, and the sizes of skin tumors were similar in all three treatment groups of Skh:1 mice (whether placebo or TA-65 supplementation began before and continued during and after the inciting UVB exposure or TA-65 given only after UVB-induced skin cancers appeared), indicating that oral telomerase activator TA- 65 supplementation does not significantly influence UV-induced skin carcinogenesis. This is indeed encouraging because a possible adverse effect of dietary telomerase might have been the enhancement of tumorigenesis. In fact, many researchers (who have themselves demonstrated the efficacy of TA-65 in slowing age-related diseases and cellular senescence and possibly even mortality) realize the importance of ensuring "that administration of a telomerase activator does not increase susceptibility to / or risk for cancer or cancer related diseases" [59]. Because skin cancer is by far the most common human cancer, the absence of any change in the magnitude of skin cancer incidence with oral TA-65 attests to the safety of this supplement.

\section{Acknowledgments}

We thank Calvin Bruce Harley, Ph.D., for sponsoring this research through TA Sciences. We are grateful to Robert M. Nakamura, M.D. (formerly Chairman of the Department of Pathology, Scripps Clinic and Research Foundation, La Jolla, CA 97037, now deceased) for collaboration in histologic examination of tumor tissues. We also especially thank Heather Nolan, M.A., for excellent editing of the text and assistance in literature research.

\section{Author Contributions}

Karen E. Burke, M.D., Ph.D. (KEB), conceptualized, acquired the funding, supervised, and administered this research. Xueyan Zhou, M.D, M.S. (XZ), with KEB performed the laboratory investigation (enhancing the protocol when indicated) and curated the data. Yongyun Wang, Ph.D. (YW) did the statistical analysis. KEB and XZ collected the data and together with the statistician YW analyzed this data. Huachen Wei, M.D., Ph.D. (HW), provided scientific advice about the protocol and analyses as well as laboratory space and animal facilities. All authors reviewed and edited the protocol prior to the investigation, critically reviewed the intellectual content and presentation of research data and analysis, and revised, edited, and approved the final manuscript. As principal author, KEB did design the study and decide to publish with the consent of all co-authors but with no involvement from the supporting source. KEB with coauthors $X Z$ and $Y W$ prepared the manuscript which all coauthors read and revised when indicated. All authors ensure the accuracy and integrity of the work.

\section{Funding}

We thank TA Sciences (www.TASciences.com) for financial support (Grant TAS 2001 KBURKE) which provided the TA-65 supplement, compensated all laboratory, histology, and animal care fees, and provided support in the form of salary to coauthor XZ. TA Sciences did not have any additional role in the study design, data collection and analysis, decision to publish, or preparation of the manuscript. The specific roles of each of these coauthors are articulated in the "Author 
Contributions" section. The Karen E. Burke Research Foundation (no specific grant identification number) funded the consultant fees for YW as well as the manuscript preparation fees. KEB and HW received no personal compensation or salary for this study. None of the authors have any competing or commercial interests that would in any way bias this study.

\section{Competing Interests}

None of the authors have any competing interests or any financial, non-financial, professional, or personal competing interests that would bias this research. Please note that $\mathrm{YW}$ was chosen as a consultant to do the statistical analysis of the data because he had previously worked in our laboratory and had collaborated on statistical analysis for other past publications with similar protocols to study the prevention of skin cancer by topical and oral antioxidants. His current commercial affiliation (employment) at Medtronic Diabetes is in no way associated with the research presented in this publication. His employment does not in any way alter adherence to the policies of $O B M$ Geriatrics on sharing data and/or materials. The sponsor of this research was TA Sciences through Calvin Bruce Harley, Ph.D., who did not participate in the specific study design (except to advise supplement dose) or in the collection, analysis, or interpretation of data. He has no conflict of interest regarding this manuscript.

\section{References}

1. Chan SR, Blackburn EH. Telomeres and telomerase. Philos Trans R Soc Lond B Biol Sci. 2004; 359: 109-122.

2. Greider $\mathrm{CW}$, Blackburn $\mathrm{EH}$. A telomeric sequence in the RNA of tetrahymena telomerase required for telomere repeat synthesis. Nature. 1989; 337: 331-337.

3. de Jesus BB, Schneeberger K, Vera E, Tejera A, Harley CB, Blasco MA. The telomerase activator TA-65 elongates short telomeres and increases health span of adult/old mice without increasing cancer incidence. Aging cell. 2011; 10: 604-621.

4. Wright DL, Jones EL, Mayer JF, Oehninger S, Gibbons WE, Lanzendorf SE. Characterization of telomerase activity in the human oocyte and preimplantation embryo. Mol Hum Reprod. 2001; 7: 947-955.

5. Ulaner GA, Giudice LC. Developmental regulation of telomerase activity in human fetal tissues during gestation. Mol Hum Reprod. 1997; 3: 769-773.

6. Harley CB. Telomerase is not an oncogene. Oncogene. 2002; 21: 494-502.

7. Flores I, Benetti R, Blasco MA. Telomerase regulation and stem cell behaviour. Curr Opin Cell Biol. 2006; 18: 254-260.

8. Harley CB, Liu W, Blasco M, Vera E, Andrews WH, Briggs LA, et al. A natural product telomerase activator as part of a health maintenance program. Rejuvenation Res. 2011; 14: 45-56.

9. Hayflick L, Moorhead PS. The serial cultivation of human diploid cell strains. Exp Cell Res. 1961; 25: 585-621.

10. Harley $\mathrm{CB}$, Futcher $\mathrm{AB}$, Greider $\mathrm{CW}$. Telomeres shorten during ageing of human fibroblasts. Nature. 1990; 345: 458-460.

11. Epel ES, Blackburn EH, Lin J, Dhabhar FS, Adler NE, Morrow JD, et al. Accelerated telomere shortening in response to life stress. Proc Natl Acad Sci USA. 2004; 101: 17312-17315. 
12. Epel ES. Psychological and metabolic stress: A recipe for accelerated cellular aging? Hormones. 2009; 8: 7-22.

13. Von Zglinicki T. Oxidative stress shortens telomeres. Trends Biochem Sci. 2002; 27: 339-344.

14. Effros RB. Genetic alterations in the ageing immune system: Impact on infection and cancer. Mech Ageing Dev. 2003; 124: 71-77.

15. Spyridopoulos I, Hoffmann J, Aicher A, Brümmendorf TH, Doerr HW, Zeiher AM, et al. Accelerated telomere shortening in leukocyte subpopulations of patients with coronary heart disease: Role of cytomegalovirus seropositivity. Circulation. 2009; 120: 1364-1372.

16. Lichterfeld M, Mou D, Cung TD, Williams KL, Waring MT, Huang J, et al. Telomerase activity of HIV-1-specific CD8 ${ }^{+}$T cells: Constitutive up-regulation in controllers and selective increase by blockade of PD ligand 1 in progressors. Blood. 2008; 112: 3679-3687.

17. Fauce SR, Jamieson BD, Chin AC, Mitsuyasu RT, Parish ST, Ng HL, et al. Telomerase-based pharmacologic enhancement of antiviral function of human $\mathrm{CD}^{+} \mathrm{T}$ lymphocytes. J Immunol. 2008; 181: 7400-7406.

18. Pawelec G, Derhovanessian E, Larbi A, Strindhall J, Wikby A. Cytomegalovirus and human immunosenescence. Rev Med Virol. 2009; 19: 47-56.

19. Garcia CK, Wright WE, Shay JW. Human diseases of telomerase dysfunction: Insights into tissue aging. Nucleic Acids Res. 2007; 35: 7406-7416.

20. Armanios MY, Chen JJ, Cogan JD, Alder JK, Ingersoll RG, Markin C, et al. Telomerase mutations in families with idiopathic pulmonary fibrosis. N Engl J Med. 2007; 356: 1317-1326.

21. Calado RT, Young NS. Telomere diseases. N Engl J Med. 2009; 361: 2353-2365.

22. Savage SA, Alter BP. The role of telomere biology in bone marrow failure and other disorders. Mech Ageing Dev. 2008; 129: 35-47.

23. Calado RT. Telomeres and marrow failure. Hematology Am Soc Hematol Educ Program. 2009; 2009: 338-343.

24. Willeit P, Raschenberger J, Heydon EE, Tsimikas S, Haun M, Mayr A, et al. Leucocyte telomere length and risk of type 2 diabetes mellitus: New prospective cohort study and literature-based meta-analysis. PloS one. 2014; 9: E112483.

25. Aviv A, Valdes A, Gardner JP, Swaminathan R, Kimura M, Spector TD. Menopause modifies the association of leukocyte telomere length with insulin resistance and inflammation. J Clin Endocrinol Metab. 2006; 91: 635-640.

26. Hastie ND, Dempster M, Dunlop MG, Thompson AM, Green DK, Allshire RC. Telomere reduction in human colorectal carcinoma and with ageing. Nature. 1990; 346: 866-868.

27. Cawthon RM, Smith KR, O'Brien E, Sivatchenko A, Kerber RA. Association between telomere length in blood and mortality in people aged 60 years or older. Lancet. 2003; 361: 393-395.

28. Razgonova MP, Zakharenko AM, Golokhvast KS, Thanasoula M, Sarandi E, Nikolouzakis K, et al. Telomerase and telomeres in aging theory and chronographic aging theory. Mol Med Rep. 2020; 22: 1679-1694.

29. Zhu J, Wang H, Bishop JM, Blackburn EH. Telomerase extends the lifespan of virus-transformed human cells without net telomere lengthening. Proc Natl Acad Sci USA. 1999; 96: 3723-3728.

30. Stewart SA, Hahn WC, O'Connor BF, Banner EN, Lundberg AS, Modha P, et al. Telomerase contributes to tumorigenesis by a telomere length-independent mechanism. Proc Natl Acad Sci U.S.A. 2002; 99: 12606-12611. 
31. García-Castillo J, Alcaraz-Pérez F, Martínez-Balsalobre E, García-Moreno D, Rossmann MP, Fernández-Lajarín $\mathrm{M}$, et al. Telomerase RNA recruits RNA polymerase II to target gene promoters to enhance myelopoiesis. Proc Natl Acad Sci U.S.A. 2021; 118: E2015528118.

32. Salvador L, Singaravelu G, Harley CB, Flom P, Suram A, Raffaele JM. A natural product telomerase activator lengthens telomeres in humans: $\mathrm{A}$ randomized, double blind, and placebo controlled study. Rejuvenation Res. 2016; 19: 478-484.

33. Reichert S, Bize P, Arrivé M, Zahn S, Massemin S, Criscuolo F. Experimental increase in telomere length leads to faster feather regeneration. Exp Gerontol. 2014; 52: 36-38.

34. Dow CT, Harley CB. Evaluation of an oral telomerase activator for early age-related macular degeneration-a pilot study. Clin Ophthalmol. 2016; 10: 243-249.

35. Szabo NJ. Dietary safety of cycloastragenol from Astragalus spp.: Subchronic toxicity and genotoxicity studies. Food Chem Toxicol. 2014; 64: 322-334.

36. Harley CB, Liu W, Flom PL, Raffaele JM. A natural product telomerase activator as part of a health maintenance program: Metabolic and cardiovascular response. Rejuvenaton Res. 2013; 16: 386-395.

37. Singaravelu G, Harley CB, Raffaele JM, Sudhakaran PS, Suram A. Double-Blind, placebocontrolled, randomized clinical trial demonstrates telomerase activator TA-65 decreases immunosenescent CD8+ CD28-T cells in humans. OBM Geriatrics. 2021; 5: 13.

38. Molgora B, Bateman R, Sweeney G, Finger D, Dimler T, Effros RB, et al. Functional assessment of pharmacological telomerase activators in human T cells. Cells. 2013; 2: 57-66.

39. Thomas NE, Edmiston SN, Tsai YS, Parker JS, Googe PB, Busam KJ, et al. Utility of TERT promoter mutations for cutaneous primary melanoma diagnosis. Am J Dermatopathol. 2019; 41: 264-272.

40. Wan T, Weir EJ, Johnson M, Korolchuk VI, Saretzki GC. Increased telomerase improves motor function and alpha-synuclein pathology in a transgenic mouse model of Parkinson's disease associated with enhanced autophagy. Prog Neurobiol. 2021; 199: 101953.

41. Wei $H$, Bowen $R$, Zhang $X$, Lebwohl $M$. Isoflavone genistein inhibits the initiation and promotion of two-stage skin carcinogenesis in mice. Carcinogenesis. 1998; 19: 1509-1514.

42. SAS Institute. SAS/STAT software: Changes and enhancements, Release 6.12. Cary: SAS Institute Incorporated; 1996.

43. Walker G, Shostak J. Common statistical methods for clinical research with SAS examples. 3rd ed. Cary: SAS Institute Incorporated; 2010.

44. Rogers HW, Weinstock MA, Feldman SR, Coldiron BM. Incidence estimate of nonmelanoma skin cancer (keratinocyte carcinomas) in the US population, 2012. JAMA Dermatol. 2015; 151: 10811086.

45. Koh HK, Geller AC, Miller DR, Grossbart TA, Lew RA. Prevention and early detection strategies for melanoma and skin cancer: Current status. Arch Dermatol. 1996; 132: 436-443.

46. Parkin DM, Mesher D, Sasieni P. 13. Cancers attributable to solar (ultraviolet) radiation exposure in the UK in 2010. Br J Cancer. 2011; 105: S66-S69.

47. American Cancer Society. What are basal and squamous cell skin cancers? [Internet]. Atlanta: American Cancer Society; 2019 [cited date 2018 January 31]. Availbable from: https://www.cancer.org/cancer/basal-and-squamous-cell-skin-cancer/about/what-is-basaland-squamous-cell.html.

48. Mohan SV, Chang AL. Advanced basal cell carcinoma: Epidemiology and therapeutic innovations. Curr Dermatol Rep. 2014; 3: 40-45. 
49. Mansouri $B$, Housewright $C D$. The treatment of actinic keratoses-the rule rather than the exception. JAMA Dermatol. 2017; 153: 1200.

50. Ventura A, Pellegrini C, Cardelli L, Rocco T, Ciciarelli V, Peris K, et al. Telomeres and telomerase in cutaneous squamous cell carcinoma. Int J Mol Sci. 2019; 20: 1333.

51. Burke KE, Combs Jr GF, Gross EG, Bhuyan KC, Abu-Libdeh H. The effects of topical and oral Lselenomethionine on pigmentation and skin cancer induced by ultraviolet irradiation. Nutr Cancer. 1992; 17: 123-137.

52. Burke KE, Clive J, Combs GF, Commisso J, Keen CL, Nakamura RM. Effects of topical and oral vitamin $\mathrm{E}$ on pigmentation and skin cancer induced by ultraviolet irradiation in Skh: 2 hairless mice. Nutr Cancer. 2000; 38: 87-97.

53. Burke KE, Clive J, Combs Jr GF, Nakamura RM. Effects of topical L-selenomethionine with topical and oral vitamin $\mathrm{E}$ on pigmentation and skin cancer induced by ultraviolet irradiation in Skh: 2 hairless mice. J Am Acad Dermatol. 2003; 49: 458-472.

54. Zhou X, Burke KE, Wang Y, Wei H. Dietary lycopene protects SkH-1 mice against ultraviolet Binduced photocarcinogenesis. J Drugs Dermatol. 2019; 18: 1244-1254.

55. Raknerud N. The ultrastructure of the interfollicular epidermis of the hairless ( $\mathrm{hr} / \mathrm{hr}$ ) mouse. V. The cytoplasm of the horny cells. Virchows Arch B Cell Path. 1977; 24: 179-196.

56. Ley RD, Sedita BA, Grube DD, Fry RM. Induction and persistence of pyrimidine dimers in the epidermal DNA of two strains of hairless mice. Cancer Res. 1977; 37: 3243-3248.

57. Hart RW, Setlow RB, Woodhead AD. Evidence that pyrimidine dimers in DNA can give rise to tumors. Proc Natl Acad Sci USA. 1977; 74: 5574-5578.

58. Personal Communicaton, Kathryn E. Davis, MD, Department of Plastic Surgery, University of Texas Southwestern, TX, USA, 2020.

59. Eyolfson E, Malik H, Mychasiuk R. Sexually dimorphic behavioral and genetic outcomes associated with administration of TA65 (a telomerase activator) following repetitive traumatic brain injury: A pilot study. Front Neurol. 2020; 11: 98.

60. Stampfer MR, Garbe J, Levine G, Lichtsteiner S, Vasserot AP, Yaswen P. Expression of the telomerase catalytic subunit, hTERT, induces resistance to transforming growth factor $\beta$ growth inhibition in p16INK4A (-) human mammary epithelial cells. Proc Natl Acad Sci USA. 2001; 98 : 4498-4503.

61. Chiu CP, Harley CB. Replicative senescence and cell immortality: The role of telomeres and telomerase. Proc Soc Exp Biol Med. 1997; 214: 99-106.

62. Vinagre J, Almeida A, Pópulo H, Batista R, Lyra J, Pinto V, et al. Frequency of TERT promoter mutations in human cancers. Nat Commun. 2013; 4: 2185

63. Killela PJ, Reitman ZJ, Jiao Y, Bettegowda C, Agrawal N, Diaz LA, et al. TERT promoter mutations occur frequently in gliomas and a subset of tumors derived from cells with low rates of selfrenewal. Proc Natl Acad Sci USA. 2013; 110: 6021-6026.

64. Remke M, Ramaswamy V, Peacock J, Shih DJ, Koelsche C, Northcott PA, et al. TERT promoter mutations are highly recurrent in SHH subgroup medulloblastoma. Acta Neuropathol. 2013; 126: 917-929.

65. Rachakonda PS, Hosen I, De Verdier PJ, Fallah M, Heidenreich B, Ryk C, et al. TERT promoter mutations in bladder cancer affect patient survival and disease recurrence through modification by a common polymorphism. Proc Natl Acad Sci USA. 2013; 110: 17426-17431. 
66. Melo M, da Rocha AG, Vinagre J, Batista R, Peixoto J, Tavares C, et al. TERT promoter mutations are a major indicator of poor outcome in differentiated thyroid carcinomas. J Clin Endocrinol Metab. 2014; 99: E754-765.

67. Horn S, Figl A, Rachakonda PS, Fischer C, Sucker A, Gast A, et al. TERT promoter mutations in familial and sporadic melanoma. Science. 2013; 339: 959-961.

68. Huang FW, Hodis E, Xu MJ, Kryukov GV, Chin L, Garraway LA. Highly recurrent TERT promoter mutations in human melanoma. Science. 2013; 339: 957-959.

69. Horn S, Figl A, Rachakonda PS, Fischer C, Sucker A, Gast A, et al. TERT promoter mutations in familial and sporadic melanoma. Science. 2013; 339: 959-961.

70. Pópulo H, Boaventura P, Vinagre J, Batista R, Mendes A, Caldas R, et al. TERT promoter mutations in skin cancer: The effects of sun exposure and X-irradiation. J Invest Dermatol. 2014; 134: 2251-2257.

71. Scott GA, Laughlin TS, Rothberg PG. Mutations of the TERT promoter are common in basal cell carcinoma and squamous cell carcinoma. Mod Pathol. 2014; 27: 516-523.

72. Griewank KG, Murali R, Schilling B, Schimming T, Möller I, Moll I, et al. TERT promoter mutations are frequent in cutaneous basal cell carcinoma and squamous cell carcinoma. PloS one. 2013; 8: E80354.

73. Lin SY, Liao SL, Hong JB, Chu CY, Sheen YS, Jhuang JY, et al. TERT promoter mutations in periocular carcinomas: Implications of ultraviolet light in pathogenesis. Br J Ophthalmol. 2016; 100: 274-277.

74. Shain AH, Yeh I, Kovalyshyn I, Sriharan A, Talevich E, Gagnon A, et al. The genetic evolution of melanoma from precursor lesions. N Engl J Med. 2015; 373: 1926-1936.

75. Walton KE, Garfield EM, Zhang B, Quan VL, Shi K, Mohan LS, et al. The role of TERT promoter mutations in differentiating recurrent nevi from recurrent melanomas: A retrospective, casecontrol study. J Am Acad Dermatol. 2019; 80: 685-693.

76. Tetzlaff MT, Reuben A, Billings SD, Prieto VG, Curry JL. Toward a molecular-genetic classification of Spitzoid neoplasms. Clin Lab Med. 2017; 37: 431-448.

77. De Unamuno Bustos B, Sahuquillo Torralba A, Moles Poveda P, Perez Simo G, Simarro Farinos $\mathrm{J}$, Llavador Ros $\mathrm{M}$, et al. Telomerase expression in a series of melanocytic neoplasms. Estudio de la expresión de telomerasa en una serie de neoplasias melanocíticas. Actas Dermosifiliogr. 2019; 110: 212-219.

78. Griewank KG, Murali R, Puig-Butille JA, Schilling B, Livingstone E, Potrony $M$, et al. TERT promoter mutation status as an independent prognostic factor in cutaneous melanoma. J Natl Cancer Inst. 2014; 106: dju246.

79. Baltzarsen PB, Georgsen JB, Nielsen PS, Steiniche T, Stougaard M. Detection of mRNA of telomerase protein in benign naevi and melanomas using RNAscope. Appl Immunohistochem Mol Morphol. 2020; 28: 36-41.

80. Toland AE. POT1 pathogenic variants: Not all telomere pathway genes are equal in risk of hereditary cutaneous melanoma. Br J Dermatol. 2019; 181: 14-15.

81. Harland M, Petljak M, Robles-Espinoza CD, Ding Z, Gruis NA, van Doorn R, et al. Germline TERT promoter mutations are rare in familial melanoma. Fam Cancer. 2016; 15: 139-144.

82. Hugdahl E, Kalvenes MB, Mannelqvist M, Ladstein RG, Akslen LA. Prognostic impact and concordance of TERT promoter mutation and protein expression in matched primary and metastatic cutaneous melanoma. Br J Cancer. 2018; 118: 98-105. 
83. Shaughnessy $M$, Njauw $C N$, Artomov $M$, Tsao $H$. Classifying melanoma by TERT promoter mutational status. J Invest Dermatol. 2020; 140: 390-394.

84. Kabacik S, Horvath S, Cohen H, Raj K. Epigenetic ageing is distinct from senescence-mediated ageing and is not prevented by telomerase expression. Aging. 2018; 10: 2800-2815.

85. Salgado C, Roelse C, Nell R, Gruis N, van Doorn R, van der Velden P. Interplay between TERT promoter mutations and methylation culminates in chromatin accessibility and TERT expression. PloS one. 2020; 15: E0231418.

86. Nikolouzakis TK, Falzone L, Lasithiotakis K, Krüger-Krasagakis S, Kalogeraki A, Sifaki M, et al. Current and future trends in molecular biomarkers for diagnostic, prognostic, and predictive purposes in non-melanoma skin cancer. J Clinical Med. 2020; 9: 2868.

87. Srinivas N, Neittaanmäki N, Heidenreich B, Rachakonda S, Karppinen TT, Grönroos M, et al. TERT promoter mutations in actinic keratosis before and after treatment. Intl J Cancer. 2020; 146: 2932-2934.

88. Ventura A, Pellegrini C, Cardelli L, Rocco T, Ciciarelli V, Peris K, et al. Telomeres and telomerase in cutaneous squamous cell carcinoma. Internet J Molec Sciences. 2019; 20: 1333.

89. Campos MA, Macedo S, Fernandes M, Pestana A, Pardal J, Batista R, et al. TERT promoter mutations are associated with poor prognosis in cutaneous squamous cell carcinoma. J Am Acad Dermatol. 2019; 80: 660-669.

90. American Cancer Society. Cancer facts \& figures 2019 [Internet]. Atlanta: American Cancer Society; 2019. Available from: https://www.cancer.org/research/cancer-facts-statistics/allcancer-facts-figures/cancer-facts-figures-2019.html.

91. Robinson JK. Sun exposure, sun protection, and vitamin D. JAMA. 2005; 294: 1541-1543.

92. American Academy of Dermatology Association. Skin cancer [Internet]. Rosemont: American Academy of Dermatology Association; 2021 [cited date 2020 November 27]. Available from: https://www.aad.org/media/stats-skin-cancer.

93. The Skin Cancer Foundation. Skin cancer facts \& statistics [Internet]. New York City: The Skin Cancer Foundation; 2021 [cited date 2020 November 27]. Available from: https://www.skincancer.org/skin-cancer-information/skin-cancer-facts/.

94. Aggarwal $P$, Knabel $P$, Fleischer Jr AB. United States burden of melanoma and non-melanoma skin cancer from 1990 to 2019. J Am Acad Dermatol. 2021; 85: 388-395.

95. González-Suárez E, Samper E, Ramírez A, Flores JM, Martín-Caballero J, Jorcano JL, et al. Increased epidermal tumors and increased skin wound healing in transgenic mice overexpressing the catalytic subunit of telomerase, mTERT, in basal keratinocytes. EMBO J. 2001; 20: 2619-2630.

96. Tedone E, Huang E, O'Hara R, Batten K, Ludlow AT, Lai TP, et al. Telomere length and telomerase activity in T cells are biomarkers of high-performing centenarians. Aging Cell. 2019; 18: E12859.

97. Tsoukalas D, Fragkiadaki P, Docea AO, Alegakis AK, Sarandi E, Thanasoula M, et al. Discovery of potent telomerase activators: Unfolding new therapeutic and anti-aging perspectives. Molec Med Reports. 2019; 20: 3701-3708.

98. Liu P, Zhao H, Luo Y. Anti-aging implications of Astragalus membranaceus (Huangqi): A wellknown Chinese tonic. Aging Dis. 2017; 8: 868-886. 


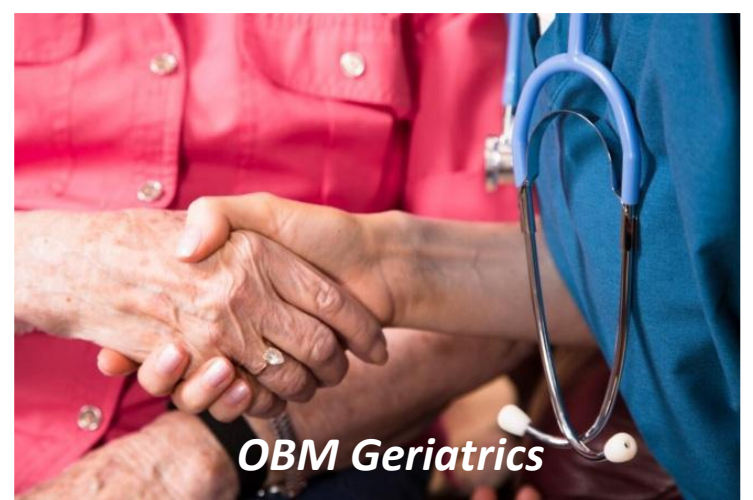

Enjoy OBM Geriatrics by:

1. Submitting a manuscript

2. Joining in volunteer reviewer bank

3. Joining Editorial Board

4. Guest editing a special issue

For more details, please visit: http://www.lidsen.com/journals/geriatrics 